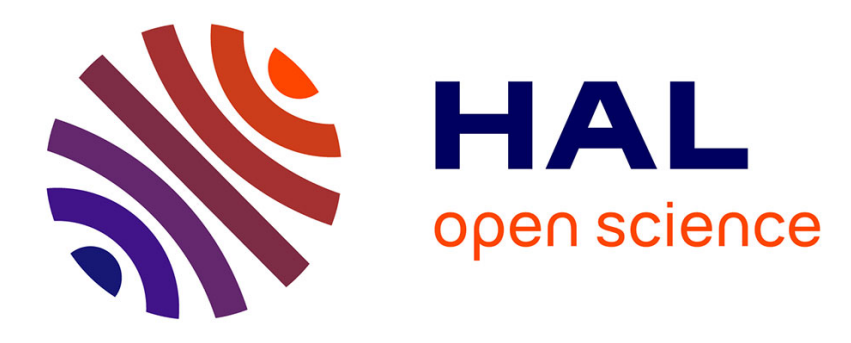

\title{
On Frege's Nightmare: A Combination of Intuitionistic, Free and Paraconsistent Logics
}

\author{
Shahid Rahman
}

\section{To cite this version:}

Shahid Rahman. On Frege's Nightmare: A Combination of Intuitionistic, Free and Paraconsistent Logics. essays on non-classical logic, 2001. halshs-01228974

\section{HAL Id: halshs-01228974 \\ https://shs.hal.science/halshs-01228974}

Submitted on 15 Nov 2015

HAL is a multi-disciplinary open access archive for the deposit and dissemination of scientific research documents, whether they are published or not. The documents may come from teaching and research institutions in France or abroad, or from public or private research centers.
L'archive ouverte pluridisciplinaire HAL, est destinée au dépôt et à la diffusion de documents scientifiques de niveau recherche, publiés ou non, émanant des établissements d'enseignement et de recherche français ou étrangers, des laboratoires publics ou privés. 


\title{
On Frege's Nightmare: A Combination of Intuitionistic, Free and Paraconsistent Logics \\ In H. Wansing: Essays on Non-Classical Logic, World Scientific, London, 2001)
}

\author{
Shahid Rahman \\ FR. 5.1 Philosophie, Universität deaas Srlandes; and \\ Archives - Centre d'Etudes et de Recherche Henry Poincaré \\ Université Nancy 2 -EP2016 du CNRS; \\ s.rahman@rz-uni.sb.de
}

\begin{abstract}
In this paper I present a dialogical formulation of free logic which allows a straightforward combination of paraconsistent and intuitionistic logic - I call this combination Frege's Nightmare. The ideas behind this combination can be expressed in few words: in an argumentation, it sometimes makes sense to restrict the use and introduction of singular terms in the context of quantification to a formal use of those terms. That is, the Proponent is allowed to use a constant for a defence (of an existential quantifier) or an attack (on a universal quantifier) iff this constant has been explicitly conceded by the Opponent. When the Opponent concedes any constant occurring in an atomic formula he concedes tertium non-datur (for this formula) to. This yield a free-logic which combines classical (for propositions with singular terms for realities ) with intuitionistic logic (for propositions with singular terms for fictions). This extended free-logic can be also combined with paraconsistent logic in such a way that contradictory objects can be included in the domain of fictions. The idea is here to combine the concept of formal use of constants in free logics and that of the formal use of elementary negations in paraconsistent logics.
\end{abstract}

\section{Aims of this paper}

Issue of this paper is a dialogical formulation of free logic which allows a straightforward combination of paraconsistent and intuitionistic logic - I call this combination Frege's Nightmare ${ }^{1}$. The ideas behind this combination can be expressed in few words: in an argumentation, it sometimes makes sense to restrict the use and introduction of singular terms in the context of quantification to a formal use of those terms. That is, the Proponent is allowed to use a constant for a defence (of an existential quantifier) or an attack (on a universal quantifier) iff this constant has been already introduced by the Opponent's attack (on a universal quantifier) or the Opponent's defence (of an existential quantifier). When the Opponent concedes any constant occurring in an atomic formula he concedes tertium non-datur (for this formula) to. This yield a free-logic which combines classical (for propositions with singular terms for realities) with intuitionistic logic (for propositions with singular terms for fictions). This extended free-logic which picks up some suggestions of Francisco Suárez theory of privatio can be also combined with paraconsistent logic in such a way that contradictory objects can be included in the domain of fictions. The idea is here to combine the concept of formal use of constants in free logics and that of the formal use of elementary negations in paraconsistent logics. $^{2}$

\footnotetext{
I adopted this name from an ironic remark made by Markus Stepanians (Saarbücken) who by the way wrote an excellent book on Freges theory of judgement (Stepanians [1998]).

Such a combination of logics may help in the reconstruction of Hugh MacColl's concept of symbolic universe:

"Let $\mathrm{e}_{1}, \mathrm{e}_{2}, \mathrm{e}_{3}$, etc. (up to any number of individuals mentioned in our argument or investigation) denote our universe of real existences. Let $0_{1}, 0_{2}, 0_{3}$, etc., denote our universe of non-existences, that is to say, of unrealities, such as centaurs, nectar, ambrosia, fairies, with self-contradictions, such as round squares, square circles, flat spheres, etc., including, I fear, the nonEuclidean geometry of four dimensions and other hyperspatial geometries. Finally, let $S_{1}, S_{2}, S_{3}$, etc., denote our Symbolic Universe, or "Universe of Discourse," composed of all things real or unreal that are named or expressed by words or other symbols in our argument or investigation [...].

When a class A belongs wholly to the class e, or wholly to the class 0 ; we may call it a pure class [...].

We may sum up briefly as follows: Firstly, when any symbol A denotes an individual; then any intelligible statement $\phi(\mathrm{A})$, containing the symbol A, implies that the individual represented by A has a symbolic existence; but whether the statement $\phi(\mathrm{A})$ implies that the individual represented by A has real existence depends upon the context. Secondly, when any symbol A denotes a class; then any intelligible statement $\phi(\mathrm{A})$, containing the symbol A implies that the whole class A has a symbolic existence; but whether the statement $\phi(\mathrm{A})$ implies that the class A is wholly real, or wholly unreal, or partly real and partly unreal, depends upon the context." (MacColl [1905], 74-77).
} 


\section{The dialogical approach to free logic}

\subsection{Dialogical free logic with and without tertium non datur.}

Dialogical logic, suggested by Paul Lorenzen in 1958 and developed by Kuno Lorenz in several papers from 1961 onwards $^{3}$ was introduced as a pragmatical semantics for both classical and intuitionistic logic.

The dialogical approach studies logic as an inherently pragmatic notion with the help of an overtly externalised argumentation formulated as a dialogue between two parties taking up the roles of an Opponent ( $\mathbf{O}$ in the following) and a Proponent (P) of the issue at stake, called the principal thesis of the dialogue. $\mathbf{P}$ has to try to defend the thesis against all possible allowed criticism (attacks) by $\mathbf{O}$, thereby being allowed to use statements that $\mathbf{O}$ may have made at the outset of the dialogue. The thesis $A$ is logically valid if and only if $\mathbf{P}$ can succeed in defending $A$ against all possible allowed criticism by the Opponent. In the jargon of game theory: $\mathbf{P}$ has a winning strategy for $A$.

The philosophical point of dialogical logic is that this approach does not understand semantics as mapping names and relationships into the real world to obtain an abstract counterpart of it, but as acting upon them in a particular way.

I will now describe an intuitionistic and a classical version of a very basic system called DFL (dialogical free logic) introduced in Rahman/Rückert/ Fischmann [1999].

Suppose the elements of first-order language are given with small letters $(a, b, c, \ldots)$ for elementary formulae, capital italic letters for formulae that might be complex $(A, B, C, \ldots)$, capital italic bold letters $(\boldsymbol{A}, \boldsymbol{B}, \boldsymbol{C}, \ldots)$ for predicators and constants $\tau_{\mathrm{i}}$. A dialogue is a sequence of labelled formulae of this first-order language that are stated by either $\mathbf{P}$ or $\mathbf{O} .{ }^{4}$ The label of a formula describes its role in the dialogue, whether it is an aggressive or a defensive act. An attack is labelled with ?n/..., while $! n / . .$. tags a defence. ( $n$ is the number of the formula the attack or defence reacts to, the dots are sometimes completed with more information. The use of indices of labels will be made clear in the following). In dialogical logic the meaning in use of the logical particles is given by two types of rules which determine their local (particle rules) and their global (structural rules) meaning. The particle rules specify for each particle a pair of moves consisting of an attack and (if possible) the corresponding defence. Each such pair is called a round. An attack opens a round, which in turn is closed by a defence if possible. Before presenting a dialogical system DFL for free logics, we need the following definition.

- A constant $\tau$ is said to be introduced by $\mathbf{X}$ if (1) $\mathbf{X}$ states a formula $A[\tau / x]$ to defend $\vee_{x} A$ or (2) $\mathbf{X}$ attacks a formula $\wedge_{x} A$ with $?_{\mathrm{n} / \tau}$, and $\tau$ has not been used in the same way before. Moreover, an atomic formula is said to be introduced by $\mathbf{X}$ if it is stated by $\mathbf{X}$ and has not been stated before.

DFL is closely related to Lorenz' standard dialogues for both intuitionistic and classical logic. The particle rules are identical, and the sets of structural rules differ in only one point, namely when determining the way constants are dealt with. Before presenting the formal definition of DFL, we should have a look at a simple propositional dialogue as an example of notational conventions:

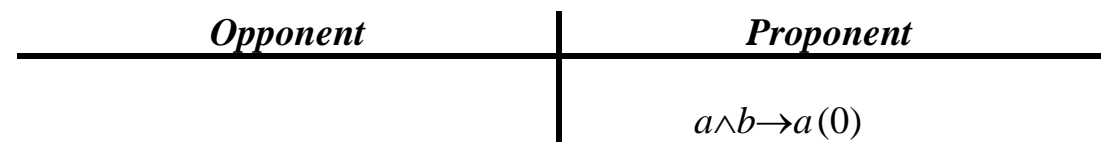

Cf. Rahman [1999] for a discussion of Hugh MacColl's ideas on symbolic existence.

Lorenzen/Lorenz [1978]. Further work has been done by Rahman [1993].

Sometimes, I use $\mathbf{X}$ and $\mathbf{Y}$ to denote $\mathbf{P}$ and $\mathbf{O}$ with $\mathbf{X} \neq \mathbf{Y}$. 

(1) $?_{0} a \wedge b$
(3) $\quad !_{2} a$

$!_{1} a$

$?_{1 / \text { left }}$

P wins

Formulae are labelled in (chronological) order of appearance. They are not listed in the order of utterance, but in such a way that every defence appears on the same level as the corresponding attack. Informally, the argument goes like this:

- P: $\quad$ "If $a$ and $b$, then $a . "$

- O: "Given $a$ and $b$, show me that $a$ holds."

- P: "If you assume $a$ and $b$, you should be able to show me that both hold. Thus show me that the left part holds."

- O: "OK,: a."

- P: "If you can say that $a$ holds, so can I."

$\mathbf{O}$ runs out of arguments, $\mathbf{P}$ wins.

PARTICLE RULES

\begin{tabular}{|c|c|c|}
\hline$\neg, \wedge, \vee, \rightarrow ; \wedge, \vee$ & $\overline{A T T A C K}$ & DEFENCE \\
\hline$\neg A$ & $?_{\mathrm{n}} A$ & $\begin{array}{l}\otimes \\
\text { (The symbol ' } \otimes \text { ' indicates } \\
\text { that no defence, but only } \\
\text { counterattack is allowed) }\end{array}$ \\
\hline \multirow[t]{2}{*}{$A \wedge B$} & $?_{\mathrm{n} / \mathrm{left}}$ & $!_{\mathrm{m}} A$ \\
\hline & $\begin{array}{c}?_{\mathrm{n} / \text { right }} \\
\text { (The attacker chooses) }\end{array}$ & $!_{\mathrm{m}} B$ \\
\hline \multirow[t]{2}{*}{$A \vee B$} & \multirow[t]{2}{*}{$?_{\mathrm{n}}$} & $!_{\mathrm{m}} A$ \\
\hline & & $\begin{array}{c}!_{\mathrm{m}} B \\
\text { (The defender chooses) }\end{array}$ \\
\hline$A \rightarrow B$ & $?_{\mathrm{n}} A$ & $!_{\mathrm{m}} B$ \\
\hline$\wedge_{x} A$ & $\begin{array}{c}?_{\mathrm{n} / \tau} \\
\text { (The attacker chooses) }\end{array}$ & $!_{\mathrm{m}} A[\tau / \mathrm{x}]$ \\
\hline$\vee_{x} A$ & $?_{\mathrm{n}}$ & $\begin{array}{c}!_{\mathrm{m} / \tau} A[\tau / \mathrm{x}] \\
\text { (The defender chooses) }\end{array}$ \\
\hline
\end{tabular}

The first row contains the form of the formula in question, the second one possible attacks against this formula, and the last one possible defences against those attacks. (The symbol " $\otimes "$ indicates that no defence is possible.). Note that ?n/... is a move -more precisely it is an attack - but not a formula. Thus if one partner in the dialogue states a conjunction, the other may initiate the attack by asking either for the left side of the conjunction ("show me that the left side of the conjunction holds", or ?n/left for short) or the right one ("show me that the right side of the conjunction holds", or ?n/right). If one partner in the dialogue states a disjunction, the other may initiate the attack by asking to be shown any side of the disjunction (?n). As already mentioned, the number in the index denotes the formula the attack refers to. The notation of defences is used in analogy to that of attacks. Rules for quantifiers work similarly. 
Next, we fix the way formulae are sequenced to form dialogues with a set of structural rules (orig. Rahmenregeln).

DFL0: Formulae are alternately uttered by $\mathbf{P}$ and $\mathbf{O}$. The initial formula is uttered by $\mathbf{P}$. It does not have a label, but provides the topic of argument. Every formula below the initial formula is either an attack or a defence against an earlier formula of the other player.

DFL1: Both $\mathbf{P}$ and $\mathbf{O}$ may only repeat attacks that change the situation: a situation (allowing the repetition of an attack) is changed if and only if $\mathbf{O}$ introduces a new atomic formula or a new constant (which can now be used by $\mathbf{P}$ ) - the intuitive idea should be clear. The precise formulation of it still need some work.

DFL2 (formal rule for atomic formulae): $\mathbf{P}$ may not introduce atomic formulae: any atomic formula must be stated by $\mathbf{O}$ first.

DFL3 (formal rule for constants): Only $\mathbf{O}$ may introduce constants.

DFL4 (winning rule): $\mathbf{X}$ wins iff it is $\mathbf{Y}$ 's turn but he cannot move (either attack or defend).

$\mathrm{DFL}_{1} 5$ (intuitionistic rule): In any move, each player may attack a (complex) formula asserted by his partner or he may defend himself against the last not already defended attack. Only the latest open attack may be answered. If it is X's turn at position $n$ and there are two open attacks $\mathrm{m}, \mathrm{l}$ such that $\mathrm{m}<$ $\mathrm{l}<\mathrm{n}$, then $\mathbf{X}$ may not defend against $\mathrm{m}^{5}$

DFL is an intuitionistic as well as a classical semantics. To obtain the classical version simply replace $\mathrm{DFL}_{5} 5$ by the following rule:

$\mathrm{DFL}_{\mathrm{C}} 5$ (classical rule)

In any move, each player may attack a (complex) formula asserted by his partner or he may defend himself against any attack (including those which have already been defended).

If we need to specify (explicitly) which system is meant, we write $\mathbf{D F} \mathbf{L}_{\mathbf{I}}$ or $\mathbf{D F} \mathbf{L}_{\mathbf{C}}$ instead of DFL.

The crucial rule that makes DFL behave like a free logic is DFL3.

To see the difference between standard and free dialogues (those with and those without DFL3, consider another example. Without DFL3, we would obtain the following dialogue proving that if nothing is a vampire, Nosferatu is no vampire:

\begin{tabular}{ll|l}
\multicolumn{2}{r|}{ Opponent } & \multicolumn{2}{|c}{ Proponent } \\
\hline & & $\wedge_{x} \neg \boldsymbol{A}_{x} \rightarrow \neg \boldsymbol{A}_{\tau}$ \\
$(1) \quad ?_{0} \wedge_{x} \neg \boldsymbol{A}_{x}$ & $!_{1} \neg \boldsymbol{A}_{\tau}$ \\
$(3) \quad ?_{2} \boldsymbol{A}_{\tau}$ & $\otimes$ & $(0)$ \\
$(5) \quad !_{4} \neg \boldsymbol{A}_{\tau}$ & $?_{1 / \tau}$ \\
& $\otimes$ & $?_{5} \boldsymbol{A}_{\tau}$ \\
& & The Proponent wins
\end{tabular}

5 Notice that this does not mean, that the last attack was the last move. 
If we play the same dialogue again in DFL, things look different:

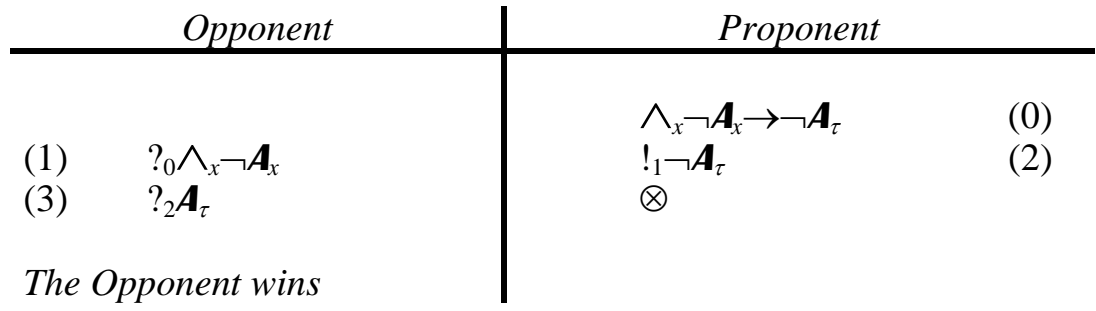

We observe that $\mathbf{P}$ runs out of arguments. He cannot attack (1) any more, because not a single constant has been introduced so far, and he may not introduce one on its own. Neither can he defend himself against the atomic formula in (3) due to the particle rule for negation.

It is obvious that the (Proponent's) thesis $\boldsymbol{A}_{\tau} \rightarrow \bigvee_{X} \boldsymbol{A}_{X}$ cannot be won. This shows that the Opponent may state a proposition about a fictive entity without committing himself to it's existence. MacColls reflections on non-existence amount to these. ${ }^{6}$

\subsection{Winning strategies and dialogical tableaux for DFL}

As already mentioned, validity is defined in dialogical logic via winning strategies of $\mathbf{P}$, i.e. the thesis $A$ is logically valid iff $\mathbf{P}$ can succeed in defending $A$ against all possible allowed criticism by $\mathbf{O}$. In this case, $\mathbf{P}$ has a winning strategy for $A$. It should be clear that the formal rule which elucidates MacColl's understanding of the problematic modality of hypotheticals, does not necessarily imply that winning a dialog with help of this rule yields the validity of the formula involved: The Proponent may win a dialogue, even formally, because the Opponent did not play the best moves. Validity, on the other hand forces the consideration of all possibilities available. A systematic description of the winning strategies available can be obtained from the following considerations:

- If $\mathbf{P}$ shall win against any choice of $\mathbf{O}$, we will have to consider two main different situations, namely the dialogical situations in which $\mathbf{O}$ has stated a complex formula and those in which $\mathbf{P}$ has stated a complex formula. We call these main situations the $\mathbf{O}$-cases and the $\mathbf{P}$-cases, respectively.

In both of these situations another distinction has to be examined:

1. $\mathbf{P}$ wins by choosing an attack in the $\mathbf{O}$-cases or a defence in the $\mathbf{P}$-cases, iff he can win at least one of the dialogues he has chosen.

2. When $\mathbf{O}$ can choose a defence in the $\mathbf{O}$-cases or an attack in the $\mathbf{P}$-cases, $\mathbf{P}$ can win iff he can win all of the dialogues $\mathbf{O}$ can choose.

The closing rules for dialogical tableaux are the usual ones: a branch is closed iff it contains two copies of the same formula, one stated by $\mathbf{O}$ and the other one by $\mathbf{P}$. A tree is closed iff each branch is closed.

For the intuitionistic tableaux, the structural rule about the restriction on defences has to be considered. The idea is quite simple: the tableaux system allows all the possible defences (even the atomic ones) to be written down, but as soon as determinate formulae (negations, conditionals, universal quantifiers) of $\mathbf{P}$ are attacked all others will be deleted - this is an implementation of the last attack rule of . Clearly, if an attack on a $\mathbf{P}$-statement causes the deletion of the others, then $\mathbf{P}$ can also answer the last attack. Those formulae which compel the rest of $\mathbf{P}$ 's formulae to be deleted will be

M. Astroh's thorough discussion of MacColl's conception of existence (Astroh [1986], 1399-1401) amounts to the failure of this thesis in DFL. 
indicated with the expression " $\sum_{[0]}$ " which reads in the set $\sum$ save the $\mathbf{O}$ 's formulae and delete all of P's formulae stated before.

To obtain a tableaux system for DFL from those described above, add the following restriction to the closing rules and recall the rule DFL3 for constants.

- DFL-restriction

Check that for every step in which $\mathbf{P}$ chooses a constant (i.e. for every $\mathbf{P}$-attack on a universally quantified $\mathbf{O}$-formula and for every $\mathbf{P}$-defence of an existentially quantified $\mathbf{P}$-formula) this constant has been already introduced by $\mathbf{O}$ (by means of an $\mathbf{O}$-attack on a universally quantified $\mathbf{P}$ formula or a defence of an existentially quantified $\mathbf{O}$-formula).

This restriction can be technically implemented by a device which provides a label (namely an asterisk) for each constant introduced by $\mathbf{O}$. Thus, the DFL-restriction can be simplified in the following way:

- DFL-restriction with labels

Check that for every step in which $\mathbf{P}$ chooses a constant this constant has already been there, labelled with an asterisk.

All these considerations can be expressed by means of the tableaux systems for classical and intuitionistic DFL. $^{7}$

\section{Classical Tableaux for DFL}

\begin{tabular}{|c|c|}
\hline (O)-Cases & (P)-Cases \\
\hline$\sum,(\mathrm{O}) A \vee B$ & $\sum,(\mathrm{P}) A \vee B$ \\
\hline$\sum,<(\mathrm{P})_{?}>(\mathrm{O}) A \mid \sum,<(\mathrm{P})_{?}>(\mathrm{O}) B$ & $\begin{array}{l}\sum,<(\mathrm{O})_{?}>(\mathrm{P}) A \\
\left(\sum,<(\mathrm{O})_{?}>(\mathrm{P}) B\right)\end{array}$ \\
\hline$\sum,(\mathrm{O}) A \wedge B$ & $\sum,(\mathrm{P}) A \wedge B$ \\
\hline $\begin{array}{c}\sum,<(\mathrm{P})_{\text {?left }}>(\mathrm{O}) A \\
\left(\sum,<(\mathrm{P})_{\text {?right }}>(\mathrm{O}) B\right)\end{array}$ & $\sum,<(\mathrm{O})_{\text {?left }}>(\mathrm{P}) A \mid \sum,<(\mathrm{O})_{\text {?right }}>(\mathrm{P}) B$ \\
\hline$\sum,(\mathrm{O}) A \rightarrow B$ & $\sum,(\mathrm{P}) A \rightarrow B$ \\
\hline$\sum,(\mathrm{P}) A \ldots \mid<(\mathrm{P}) A>(\mathrm{O}) B$ & $\sum,(\mathrm{O}) A ;(\mathrm{P}) B$ \\
\hline$\sum,(\mathrm{O}) \neg A$ & $\sum,(\mathrm{P}) \neg A$ \\
\hline$\sum,(\mathrm{P}) A ; \otimes$ & $\sum,(\mathrm{O}) A ; \otimes$ \\
\hline$\sum,(\mathrm{O}) \wedge_{X} A$ & $\sum,(\mathrm{P}) \wedge_{x} A$ \\
\hline $\begin{array}{l}\sum,<(\mathrm{P})_{? \tau}>(\mathrm{O}) A_{\left[\tau^{*} \times \mathrm{x}\right]} \\
\tau \text { has been labelled with } \\
\text { an asterisk before }\end{array}$ & $\begin{array}{c}\sum,<(\mathrm{O})_{? \tau^{*}}>(\mathrm{P}) A_{\left[\tau^{*} / \mathrm{x}\right] \tau} \\
\tau \text { is new }\end{array}$ \\
\hline
\end{tabular}

See details on how to build tableaux systems from dialogues in Rahman [1993] and Rahman and Rückert [1997]. The use of these tableaux systems follows the very well-known analytic trees of Raymund Smullyan [1968]. Find proofs for correctness and completeness for intuitionistic strategy-tableaux-systems in Rahman [1993]. Another proof have been given by Walter Felscher in Felscher [1985]. 


$$
\begin{gathered}
\sum,(\mathrm{O}) \vee_{x} A \\
\sum, \begin{array}{c}
(\mathrm{P})_{?}>(\mathrm{O}) A_{\left[\tau^{*} / \mathrm{x}\right]} \\
\tau \text { is new }
\end{array}
\end{gathered}
$$

$$
\begin{gathered}
\sum,(\mathrm{P}) \vee_{x} A \\
-\sum_{-},<(\mathrm{O})_{?}>(\mathrm{P}) A_{[\tau / x]} \\
\tau \text { has been labelled with } \\
\text { an asterisk before }
\end{gathered}
$$

By a dialogically signed formula I mean $(\mathbf{P}) X$ or $(\mathbf{O}) X$ where $X$ is a formula. If $\Sigma$ is a set of dialogically signed formulae and $X$ is a dialogically single signed formula, I will write $\sum \cup\{X\}$ as $\sum, X$.

The exterior brackets occurring in an expression of the Form for example $\left(\sum,<(\mathbf{P})>(\mathbf{O}) B\right)$ signalise that if there is a winning strategy for $B$, then an argumentation for $A$ will be redundant and vice versa.

Observe that the formulae below the line represent pairs of attack-defence moves. In other words, they represent rounds.

Note that the expressions between the symbols ' $<$ ' and ' $>$ ', such as $\left\langle(\mathbf{P})_{?}\right\rangle,\left\langle(\mathbf{O})_{?}\right\rangle$ or $\langle(\mathbf{P}) A>$ are moves - more precisely they are attacks but not statements.

a) If $\Psi$ is a set of dialogically signed formulae, we say one of the above rules, call it rule R, applies to $\Delta$ if by appropriate substitution of $\sum, A$ [and $B$ ] the collection of signed formulae above the line in the rule $\mathrm{R}$ becomes $\Delta$.

b) By an application of rule $\mathrm{R}$ to the set $\Delta$ we mean the replacement of $\Psi$ by $\Psi_{1}$ (or by $\Psi_{1}$ and $\Psi_{2}$ - in the case that $\mathrm{R}$ is branching rule of form $\sum, \ldots \mid \sum, \ldots$ ) where $\Psi$ is the set of formulae above the line in rule $\mathrm{R}$ (after suitable substitution of $\sum, A$ [and $\left.B\right]$ ) and $\Psi_{1}$ (or $\Psi_{1}$ and $\Psi_{2}$ ) is (are) the set of formulae below.

c) By a strategy-tree I mean a finite collection $\left\{\sum_{1}, \sum_{2}, \ldots, \sum_{n}\right\}$ of sets of dialogically signed formulae.

d) By an application of the rule $\mathrm{R}$ to the strategy-tree $\left\{\Sigma_{1}, \Sigma_{2}, \ldots, \sum_{n}\right\}$ I mean the replacement of this strategytree with a new one which is like the first except for containing instead of some $\sum_{\mathrm{i}}$ the result (or results) of applying rule $\mathrm{R}$ to $\sum_{\mathrm{i}}$.

e) By a strategy-tableau I mean a finite sequence of strategy-trees $\Omega_{1}, \Omega_{2}, \ldots, \Omega_{\mathrm{n}}$ in which each strategy-tree except the first is the result of applying one of the above rules to the preceding strategy-tree.

f) A set $\sum$ of dialogically signed formulae is closed if it contains both $\mathrm{O} X$ and $\mathrm{P} X$ for some formula $\mathrm{X}$.

\begin{tabular}{|c|c|}
\hline (O)-Cases & (P)-Cases \\
\hline$\sum,(\mathrm{O}) A \vee B$ & $\sum,(\mathrm{P}) A \vee B$ \\
\hline$\sum,<(\mathrm{P})_{?}>(\mathrm{O}) A \mid \sum,<(\mathrm{P})_{?}>(\mathrm{O}) B$ & $\begin{array}{c}\sum,<(\mathrm{O})_{?}>(\mathrm{P}) A \\
\left(\sum,<(\mathrm{O})_{?}>(\mathrm{P}) B\right)\end{array}$ \\
\hline$\sum,(\mathrm{O}) A \wedge B$ & $\sum,(\mathrm{P}) A \wedge B$ \\
\hline $\begin{array}{c}\sum,<(\mathrm{P})_{\text {?left }}>(\mathrm{O}) A \\
\left(\sum,<(\mathrm{P})_{\text {?right }}>(\mathrm{O}) B\right)\end{array}$ & $\sum,<(\mathrm{O})_{\text {?left }}>(\mathrm{P}) A \mid \sum,<(\mathrm{O})_{\text {?right }}>(\mathrm{P}) B$ \\
\hline$\sum,(\mathrm{O}) A \rightarrow B$ & $\sum,(\mathrm{P}) A \rightarrow B$ \\
\hline$\sum,(\mathrm{P}) A \ldots \mid<(\mathrm{P}) A>(\mathrm{O}) B$ & $\sum_{[\mathrm{O}]},(\mathrm{O}) A ;(\mathrm{P}) B$ \\
\hline
\end{tabular}

g) A strategy-tree $\left\{\sum_{1}, \sum_{2}, \ldots, \sum_{\mathrm{n}}\right\}$ is closed if each $\sum_{\mathrm{i}}$ in it is closed.

h) A strategy-tableau $\Omega_{1}, \Omega_{2}, \ldots, \Omega_{\mathrm{n}}$ is closed if some strategy-tree $\Omega_{\mathrm{i}}$ in it is closed.

i) By a tableau for a set $\sum$ of dialogically signed formulae I mean a tableau $\Omega_{1}, \Omega_{2}, \ldots, \Omega_{\mathrm{n}}$ in which $\Omega_{1}$ is $\left\{\sum\right\}$.

j) The formula $A$ is winnable if there is a closed tableau for $\{(\mathbf{P}) A\}$.

\section{Intuitionistic Tableaux for DFL}




\begin{tabular}{|c|c|}
\hline$\sum,(\mathrm{O}) \neg A$ & $\sum,(\mathrm{P}) \neg A$ \\
\hline$\sum,(\mathrm{P}) A ; \otimes$ & $\Sigma_{[\mathrm{O}]},(\mathrm{O}) A ; \otimes$ \\
\hline$\sum,(\mathrm{O}) \wedge_{x} A$ & $\sum,(\mathrm{P}) \wedge_{x} A$ \\
\hline $\begin{array}{c}\sum,<(\mathrm{P})_{?_{\tau}}>(\mathrm{O}) A_{\left[\tau^{*} / \mathrm{x}\right]} \\
\tau \text { has been labelled with } \\
\text { an asterisk before } \\
\sum,(\mathrm{O}) \vee_{x} A\end{array}$ & $\begin{array}{c}\sum_{[\mathrm{O}]},<(\mathrm{O})_{? \tau^{*}}>(\mathrm{P}) A_{\left[\tau^{*} / \mathrm{x}\right]} \\
\tau \text { is new } \\
\sum,(\mathrm{P}) \vee_{x} A\end{array}$ \\
\hline $\begin{array}{c}\sum,<(\mathrm{P})_{?}>(\mathrm{O}) A_{\left[\tau^{*} / \mathrm{x}\right]} \\
\tau \text { is new }\end{array}$ & $\begin{array}{l}\quad \sum,<(\mathrm{O})_{?}>(\mathrm{P}) A_{[\tau / \mathrm{x}]} \\
\tau \text { has been labelled with } \\
\text { an asterisk before }\end{array}$ \\
\hline
\end{tabular}

a) The expressions ' $\Sigma$, $\mathbf{O A}$ ', ' $\Sigma_{\mathbf{O}}, \mathbf{O A}$ ' and ' $\Sigma_{\mathbf{O}}$, $\mathbf{P A}$ ' stand for the sets $\Sigma \cup\{\mathbf{O A}\}, \Sigma_{\mathbf{O}} \cup\{\mathbf{O A}\}$ und $\Sigma_{\mathbf{O}} \cup\{\mathbf{P A}\}$.

Let us look at two examples, namely one for classical DFL and one for intuitionistic DFL:

(P) $\quad \wedge_{x} \neg \boldsymbol{A}_{x} \rightarrow \neg \boldsymbol{A}_{\tau}$

(O) $\quad \wedge_{x} \neg \boldsymbol{A}_{x}$

(P) $\neg \boldsymbol{A}_{t}$

(O) $\boldsymbol{A}_{t}$

The tableau remains open as $\mathbf{P}$ cannot choose $\tau$ to attack the universal quantifier of $\mathbf{O}$. The following intuitionistic tableau is slightly more complex:

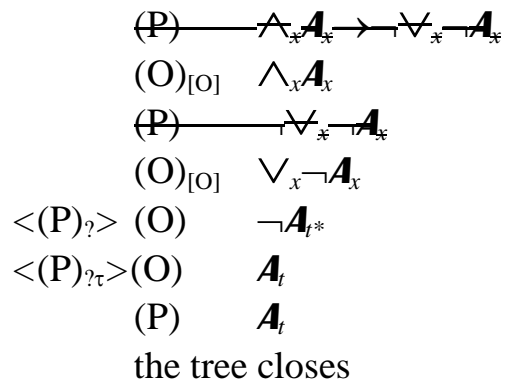

\subsection{Many quantifiers and sorts of objects The systems DFL $^{\mathbf{n}}$ and $\mathrm{DFL}^{<\mathrm{n}>}$}

Consider the situation expressed by the following proposition:

The novel contains a passage in which Sherlock Holmes dreams that he shot Dr. Watson.

There is an underlying reality that the novel is part of, the outer reality of the story told in the novel and an even further outer reality of the dream of the protagonist. To distinguish between the reality of Conan Doyle writing stories, Holmes' reality and the reality of Holmes' dream, we need three pairs of quantifiers expressing the three sorts of reality (or fiction), for which in a first step we do not need to assume that they introduce a order of levels of fiction or (reality). Actually MacColl, as can be read in the text quoted in 1.2, formulated a system in which different sorts of elements of the (in MacColl's words) symbolic universe are considered. Now, if the motivation of introducing a formal use of constants is, as already mentioned, an ontologically neutral treatment of these constants, it is not 
very clear why levels of reality should be considered at all. Narahari Rao, for example, thinks that such a graduation is incompatible with the very idea of logic with singular terms for fictions (Rao [1999]). Formally, the introduction of sorts of elements is very simple: Think of the pair of quantifiers of DFL as having the upper index 0 and add new pairs of quantifiers with higher indices, as many as we need to express every sort of reality (or fiction) that could possibly appear. We call the dialogical logic thus derived $\mathbf{D F L}^{\mathbf{n}}$. The new particle rules to be added to $\mathbf{D F L}$ are:

\begin{tabular}{|c|c|c|}
\hline$\wedge^{\mathrm{i}}, \vee^{\mathrm{i}}$ & ATTACK & DEFENCE \\
\hline$\wedge_{x}^{\mathrm{i}} A$ & $\begin{array}{c}?_{\mathrm{n} / \tau} \\
\text { (The attacker chooses) }\end{array}$ & $!_{\mathrm{m}} A[\tau / \mathrm{x}]$ \\
\hline$V_{x}{ }_{x} A$ & $?_{\mathrm{n}}$ & $\begin{array}{c}!_{\mathrm{m} / \tau} A[\tau / \mathrm{x}] \\
\text { (The defender chooses) }\end{array}$ \\
\hline
\end{tabular}

The extended set of quantifiers requires a new notion of introduction.

- A constant $\tau$ is said to be introduced as belonging to the sort $\mathbf{i}$ iff it is used to attack a universal quantifier of sort $\mathbf{i}$ or to defend an existential quantifier of sort $\mathbf{i}$ and has not been used in the same way before.

\section{I adapt DFL3 to DFLn:}

$\mathrm{DFL}^{\mathrm{n}} 3$ (first extended formal rule for constants)

For each sort of quantification the following rule holds: constants may only be introduced by $\mathbf{O}$.

These formulations yield a logic containing an arbitrary number of disjunct pairs of quantifiers dealing with different sorts of reality and fiction - this logic contains also the quantifiers $\exists$ and $\forall$ for which neither DFL3 nor DFLn3 hold. Because of the particle and structural rules for $\exists$ and $\forall$ it looks like these quantifiers work as in the standard logic. Actually they are very different: here they work as quantifiers without any ontological commitment at all. In the standard logic the ontological commitment is presupposed by the use of these quantifiers. Here not. In other words, the addition of the quantifiers $\exists$ and $\forall$ to DFL produces a logic where quantification over fictional entities is possible.

In some contexts, it might be useful to have a logic where these different realities are ordered in a hierarchy. We call the system that establishes this ordering $\mathbf{D F} \mathbf{L}^{<\mathbf{n}>}$; it results from modifying DFL3 again:

$\mathrm{DFL}^{<\mathrm{n}>} 3$ (second extended formal rule for constants)

$\mathbf{P}$ may introduce a constant $\tau$ on a level $\mathbf{m}$ iff $\mathbf{O}$ has introduced $\tau$ on some level $\mathbf{n}$ with $\mathbf{n}<\mathbf{m}$ before.

I leave as an exercise for the reader two examples. The first states that in DFL, whenever $\boldsymbol{A}$ has an instance in the scope of one or another $\vee$-quantifier, it has an instance in the scope of $\exists$; the second makes use of the ordering in $\mathrm{DFL}^{<\mathrm{n}>}$ :

1. $\quad\left(\vee 1_{x} \boldsymbol{A}_{x} \vee \vee_{x}^{2} \boldsymbol{A}_{x}\right) \rightarrow \exists_{x} \boldsymbol{A}_{x}$ (to be solved with DFL ${ }^{\mathrm{n}}$ )

2. $\left(\vee^{1}{ }_{x} \boldsymbol{A}_{x} \wedge \wedge_{x}^{2}\left(\boldsymbol{A}_{x} \rightarrow \boldsymbol{B}_{x}\right)\right) \rightarrow \vee^{1}{ }_{x} \boldsymbol{B}_{x}$ (to be solved with $\mathrm{DFL}^{<\mathrm{n}>}$ )

\subsection{Combining $\mathrm{DFL}_{\mathrm{I}}$ and $\mathrm{DFL}_{\mathrm{C}}$}

\subsubsection{Suárez' free logic}


The Logics $\mathbf{D F} \mathbf{L}_{\mathbf{I}}$ and $\mathbf{D F} \mathbf{L}_{\mathbf{C}}$ and have the awkward effect that we have to decide between them. Now as Stephen Read remarked in his book Thinking about Logic the realist position in classical logic has some plausability for existents which it definitively lacks for non-existents, fictional and beyond. Consider the proposition Don Quijote could whistle very loudly. Is this proposition the case or not? If one seriously believes Don Quijote is a fictional creature, one must prepared for there being no answer to this question ${ }^{8}$. Why should we presuppose tertium non datur for non-existents? One possible way of handling this problem was already mentioned in the introduction: The classical rule applies to existents and the non classical to non-existents. But how to implement this in the dialogical formulation of free logic? In answering this question I will follow an idea of the Spanish philosopher Francisco Suárez (1548-1647) about the non applicability of the tertium non datur to propositions containing privative predicators. That is, Suárez distinguishes - as Aristoteles did before - predicators which can naturally be said or not of an subject from those that can not be naturally applied to this subject. The predicator blind for example can be said of Oedipus but not of a stone: You can say of a man that he is blind because the contrary is normally the case. Suárez followed from this understanding of privative predicators that tertium non-datur does not apply in those propositions containing such predicators. Thus, some predicators apply and it can be decided if a given proposition built up from these predicators is the case or not. But some other predicators do not apply for example it does not make any sense to say of Oedipus that he is a even number or not. In other words, if you are allowed to use arbitrary predicators tertium non-datur applies, if not (as in the case of propositions with privative predicators) it doesn't. ${ }^{9}$ Suárez used his theory of privationes for existents. I do not. Nevertheless I will take his advice and will not presuppose in the context of dialogical free-logic that any predicator can be applied to any object. I will presuppose only that any predicator can be applied of any existent object. In the language of dialogical logic: if the Opponent conceded the existence of a given object by introducing a singular term he conceded also that any predicator or its negation can be said of this object.

One way to implement this is to add to the dialogical intuitionistic free logic $D F L_{I}$ the following structural rule:

\section{DFL6 (tertium non-datur for constants which have been already introduced)}

Once the Opponent has introduced a constant he conceded also that tertium non-datur holds for any predicator for this constant (we express this concession for an introduced constant $\tau$ with the disjunction $\mathfrak{R}_{\tau} \vee \neg \mathfrak{R}_{\mathfrak{b}}$ where $\mathfrak{R}$ works as a variable for a predicator which the Proponent can substitute for any suitable predicator)

This rule allows the Proponent to choose any pradicator at his convenience for the attack on the conceded tertium non-datur. This can be made clear with an example (recall that we are playing with the intutionistic rule $\mathrm{DFL}_{5} 5$ ):

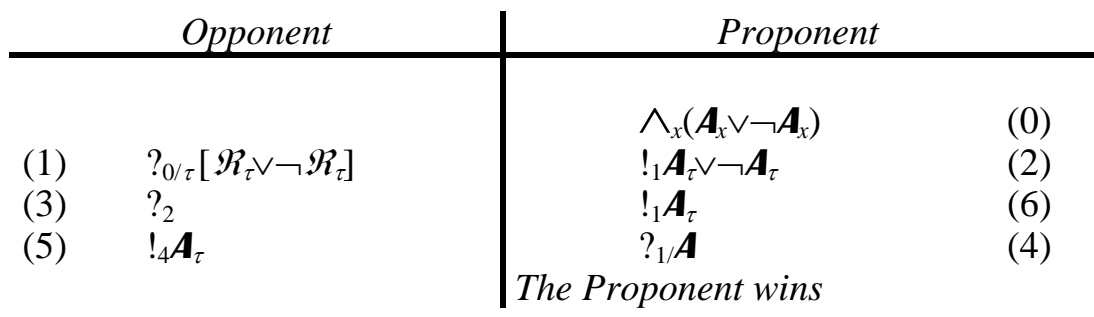

In move 1 the Opponent introduced the constant $\tau$ and conceded with this introduction the disjunction $\mathfrak{R}_{\tau} \vee \neg \mathfrak{R}_{\tau}$. In move 4 the Proponent attacks this disjunction choosing the predicator $\boldsymbol{A}$ as 
subtitution for the predicator-variable $\mathscr{R}$ and wins - the reader can easily verify that if in move 5 the Opponent chooses to defend $\neg \boldsymbol{A}_{\tau}$ he looses to.

\subsubsection{Strategies for Suárez' free logic}

The formulation of strategies is straightforward:

\begin{tabular}{|c|c|}
\hline (O)-Cases & (P)-Cases \\
\hline$\sum,(\mathrm{O}) \wedge_{X} A$ & $\sum,(\mathrm{P}) \wedge_{x} A$ \\
\hline $\begin{array}{l}\sum,<(\mathrm{P})_{? \tau}>(\mathrm{O}) A_{\left.\left[\tau^{*} \times\right]\right]} \\
\tau \text { has been labelled with } \\
\text { an asterisk before }\end{array}$ & $\begin{array}{c}\sum_{[\mathrm{O}]}\left[\Re_{\tau} \vee \neg \mathfrak{R}_{\tau}\right],<(\mathrm{O})_{?_{\tau^{*}}}>(\mathrm{P}) A_{\left[\tau^{*} / \mathrm{x}\right] \tau} \\
\tau \text { is new occurs in } \\
\text { (The disjunction } \mathfrak{R}_{\tau} \vee \neg \mathfrak{R}_{\tau} \text { occurs in } \sum_{[\mathrm{O}]} \text { ) }\end{array}$ \\
\hline$\sum,(\mathrm{O}) \bigvee_{x} A$ & $\sum,(\mathrm{P}) \bigvee_{x} A$ \\
\hline $\begin{array}{c}\sum\left[\mathfrak{R}_{\tau} \vee \neg \mathfrak{R _ { \tau } ] ,}<(\mathrm{P})_{?}>(\mathrm{O}) A_{\left[\tau^{*} / \mathrm{x}\right]}\right. \\
\tau \text { is new } \\
\text { (The disjunction } \mathfrak{R}_{\tau} \vee \neg \mathfrak{R}_{\tau} \text { occurs in } \Sigma \text { ) }\end{array}$ & $\begin{array}{l}\quad \sum,<(\mathrm{O})_{\text {? }}>(\mathrm{P}) A_{[\tau / \mathrm{x}]} \\
\tau \text { has been labelled with } \\
\text { an asterisk before }\end{array}$ \\
\hline
\end{tabular}

I call this logic Suárez' free-logic. It is not Frege's Nightmare yet but we are near. The following step is to include contradictory objects: I will do this now.

\section{Inconsistent objects}

\subsection{Paraconsistency}

MacColl's text quoted before describes a logic containing inconsistent objects like round squares, flat spheres and so on. The Suárez' logic can deal with this objects as fictional elements. Another way of dealing with this situation is to understand arguments containing propositions about inconsistent objects as arguments in which inconsistent elementary propositions about given elements of the universe of discourse are allowed. That is, instead of allowing the use of constants which name inconsistent objects, you have arguments in which two contradictory elementary propositions are allowed - this way of thinking about inconsistent objects was posed by Richard Routley ([1979]) in his interpretation of Felix Meinong (for a brief exposition of the main ideas of Richard Routley's monumental work see Manuel Bremer [1998]). This requires a logic in which such contradictions are allowed. Such a logic was the aim of the founders of paraconsistent logic, namely the Polish logician Stanislaw Jaskowski ([1948]) and the Brazilian logician Newton C. A. da Costa ([1974]).

The work of da Costa takes the assumption that contradictions can appear in a logical system without making this system trivial. Actually this leads to the standard definition of paraconsistent logics:

\section{- Paraconsistency:}

Let us consider a theory $\mathbf{T}$ as a triple $<\mathbf{L} \mathbf{A}, \mathbf{G}>$, where $\mathbf{L}$ is a language, $\mathbf{A}$ is a set of propositions (closed formulae) of $\mathbf{L}$ called the axioms of $\mathbf{T}$, and $\mathbf{G}$ is the underlying logic of $\mathbf{T}$. We suppose that $\mathbf{L}$ has a negation symbol, and that, as usual, the theorems of $\mathbf{T}$ are derived from $\mathbf{A}$ by the rules of $\mathbf{G}$ (cf. da Costa / Bueno / French [1998a], 46).

In such a context, $\mathbf{T}$ is said to be inconsistent if it has two theorems $A$ and $\neg A$, where $A$ is a formula of $\mathbf{L} \mathbf{T}$ is called trivial if any formula of $\mathbf{L}$ is a theorem of $\mathbf{T}$. $\mathbf{T}$ is called paraconsistent if it can be 
inconsistent without being trivial. Equivalently $\mathbf{T}$ is paraconsistent if it is not the case that when $A$ and $\neg A$ hold in $\mathbf{T}$, any $B$ (from $\mathbf{L}$ ) also holds in $\mathbf{T}$.

Thus, if $\mathbf{T}$ is a paraconsistent theory it is not the case that any formula of $\mathbf{L}$ and its negation are theorems of $\mathbf{T}$. Typically, in a paraconsistent theory $\mathbf{T}$, there are theorems whose negations are not theorems of $\mathbf{T}$. Nonetheless, there are formulae which are theorems of $\mathbf{T}$ and whose negations are also theorems (da Costa / Bueno / French [1998a], 46).

Actually there are two main interpretations possible. The one, which I will call the compelling interpretation, based on a naive correspondence theory, stresses that paraconsistent theories are ontologically committed to inconsistent objects. The other, which I call the permissive interpretation, does not assume this ontological commitment of paraconsistent theories. The usual referential semantics for paraconsistent logics is not really compatible with the idea of a permissive interpretation of paraconsistency. Rahman and Carnielli ([1998]) developed a dialogical approach to paraconsistency which yields several systems called literal dialogues (shorter: L-D) and takes its permissive nonreferential interpretation seriously. I will adapt L-D to the purposes of the present paper.

\subsection{The dialogical approach to paraconsistent logic and Frege's Nightmare}

As already mentioned MacColl's symbolic universe contains non-existent objects and (formally) existent ones. Non-existent objects are in my reconstruction those objects which are named by constants that have been used - i.e. which occur in a formula stated in a dialog - without being introduced (in the sense of DFL3) before. Now, contradictory objects about objects are in MacColl's view to be included in the subuniverse of non-existent objects, and this is quite in the sense of a permissive interpretation of paraconsistency. Thus, I will provide the system(s) of free-logic DFL with a rule introducing paraconsistency - I call this rule the negative literal rule DFL7 - but with the following caveat:

DFL7 (negative literal rule)

The Proponent is allowed to attack the negation of an atomic (propositional) statement (the so called negative literal) if and only if the Opponent has already attacked the same statement before.

DFL8 (permissive caveat)

The negative literal rule applies only for formulae in which constants occur that have not been introduced in the sense of DFL3.

Th structural rule DFL7 can be considered analogous with the formal rule for positive literals. The idea behind this rule can be connected with MacColl's concept of symbolic existence in the following way: A contradiction between literals, say, $a$ and $\neg a$, expresses that one proposition ascribes a predicator to a given object and the other proposition denies that a predicator applies to this object. Now, if the Opponent is the one who introduces such a contradiction between literals, this contradiction can be seen as having a pure problematic modality, i.e. as being stated symbolically. This means that the Proponent - who has proposed $(a \wedge \neg a) \rightarrow \neg a$ for example- is also allowed to attack (after the Opponent's concession $a \wedge \neg a$ and the Opponents attack on $\neg a$ ) the corresponding negation $\neg a$ (and no other) of the Opponent. Expressed intuitively: "If you (the Opponent) attack my statement that the figure $\mathbf{a}$ is not flat conceding that $\mathbf{a}$ is flat, so can I (the Proponent)". 
When I want to distinguish between the intuitionistic and the classical version I write $\mathbf{L}-\mathbf{D}^{\mathbf{i}}$ (for the intuitionistic version) and $\mathbf{L}-\mathbf{D}^{\mathbf{C}}$ (for the classical version). To be precise we should call these logical systems literal dialogues with classical structural rule and literal dialogues with intuitionistic structural rule respectively. Actually strictu sensu they are neither classical nor intuitionistic because neither in $\mathbf{L}^{-\mathbf{D}^{\mathbf{i}}}$ nor in $\mathbf{L}-\mathbf{D}^{\mathbf{C}}$ are ex falso sequitur quodlibet, $(a \rightarrow b) \rightarrow((a \rightarrow \neg b) \rightarrow \neg a)$, or $a \rightarrow \neg \neg a$ winnable.

In $\mathbf{L}-\mathbf{D}$ the (from a paraconsistent point of view) dangerous formulae $(a \wedge \neg a) \rightarrow b, a \rightarrow(\neg a \rightarrow b)$ and $(a \rightarrow b) \rightarrow((a \rightarrow \neg b) \rightarrow \neg a)$ are not valid. Let us see the corresponding literal dialogues in $\mathbf{L}-\mathbf{D}^{\mathbf{C}}$ for the first and the last one:

\begin{tabular}{l|ll} 
Opponent & \multicolumn{2}{|c}{ Proponent } \\
\hline & $(a \wedge \neg a) \rightarrow b$ & (0) \\
(1) $\quad ?_{0} a \wedge \neg a$ & & \\
(3) $\quad !_{2} a$ & $?_{1 / \text { left }}$ & $(2)$ \\
(5) $\quad !_{2} \neg a$ & $?_{1 / \text { right }}$ & (4) \\
The Opponent wins & &
\end{tabular}

The Proponent loses because he is not allowed to attack the move (5) (see negative literal rule). In other words, the Opponent has stated the contradiction $a \wedge \neg a$ about an object but this contradiction, being conceded as part of the symbolic reasoning in the argument, cannot be attacked by the Proponent until the Opponent starts an attack on the negative literal $\neg a$ - an attack which in this case will not take place.

Similar considerations hold for $(a \rightarrow b) \rightarrow((a \rightarrow \neg b) \rightarrow \neg a)$ :

\begin{tabular}{ll|l}
\multicolumn{2}{c|}{ Opponent } & \multicolumn{2}{|c}{ Proponent } \\
\hline & & $(a \rightarrow b) \rightarrow((a \rightarrow \neg b) \rightarrow \neg a)$ \\
& & $(0)$ \\
(1) $\quad ?_{0} a \rightarrow b$ & $!_{1}(a \rightarrow \neg b) \rightarrow \neg a \quad$ (2) \\
(3) $\quad ?_{2} a \rightarrow \neg b$ & $\otimes$ & \\
(5) $\quad ?_{4} a$ & $?_{1} a$ & \\
(7) $\quad !_{6} b$ & $?_{3} a$ & \\
(9) $\quad !_{8} \neg b$ &
\end{tabular}

The Proponent loses here because he cannot attack $\neg b$.

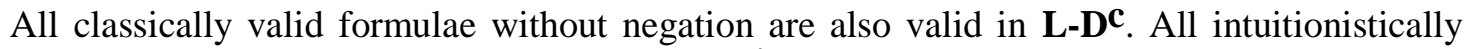
valid formulae without negation are also valid in $\mathbf{L}_{\mathbf{D}} \mathbf{D}^{\mathbf{i}}$. As in da Costa's system $\mathbf{C}_{\mathbf{1}}$ neither of the following are valid in $\mathbf{L}-\mathbf{D}^{\mathbf{c}}$ :

$$
\begin{array}{ll}
(a \wedge \neg a) \rightarrow b & (a \rightarrow(b \vee c)) \rightarrow((a \wedge \neg b) \rightarrow c) \\
(a \wedge \neg a) \rightarrow \neg b & ((a \rightarrow \neg a) \wedge(\neg a \rightarrow a)) \rightarrow \neg b \\
\neg(a \wedge \neg a) & ((a \wedge b) \rightarrow c) \rightarrow((a \wedge \neg c) \rightarrow \neg b) \\
a \rightarrow \neg \neg a & (a \rightarrow b) \vee(\neg a \rightarrow b) \\
(a \rightarrow b) \rightarrow((a \rightarrow \neg b) \rightarrow \neg a) & ((a \vee b) \wedge \neg a)) \rightarrow b \\
((a \rightarrow b) \wedge(a \rightarrow \neg b)) \rightarrow \neg a & (a \vee b) \rightarrow(\neg a \rightarrow b) \\
((\neg a \rightarrow b) \wedge(\neg a \rightarrow \neg b)) \rightarrow a & (a \rightarrow b) \rightarrow(\neg b \rightarrow \neg a) \\
\neg a \rightarrow(a \rightarrow b) & (\neg a \vee \neg b) \rightarrow \neg(a \wedge b) \\
\neg a \rightarrow(a \rightarrow \neg b) & (\neg a \wedge \neg b) \rightarrow \neg(a \vee b)
\end{array}
$$




$$
\begin{array}{lc}
a \rightarrow(\neg a \rightarrow b) & (\neg a \vee b) \rightarrow(a \rightarrow b) \\
a \rightarrow(\neg a \rightarrow \neg b) & (a \rightarrow b) \rightarrow \neg(a \wedge \neg b) \\
((a \rightarrow \neg a) \wedge(\neg a \rightarrow a)) \rightarrow b & \neg a \rightarrow((a \vee b) \rightarrow b)
\end{array}
$$

In $\mathbf{L}-\mathbf{D}^{\mathbf{i}}$ all the intuitionistically non-valid formulae have to be added to the list, for example:

$$
\begin{aligned}
& \neg \neg A \rightarrow A \quad A \vee(A \rightarrow B) \\
& A \vee \neg A \quad A \vee((A \vee B) \rightarrow B) \\
& ((A \rightarrow B) \rightarrow A) \rightarrow A \quad \neg(A \rightarrow B) \rightarrow A
\end{aligned}
$$

The extension of literal dialogues for propositional logic to first-order quantifiers is straightforward. To build Quantified Literal Dialogues, we have only to extend the structural negative literal rule to elementary statements of first-order logic. The way to do that is to generalise the rule for elementary statements:

- (General) Negative Literal Rule:

The Proponent is allowed to attack the negation of an elementary statement (i.e., the negative literal) if and only if the Opponent has already attacked the same statement before.

Notice, that to obtain Frege's Nightmare the above mentioned permissive caveat DFL8 about the introduction of singular terms should be added to the first order paraconsistent logic:

Let us look at an example:

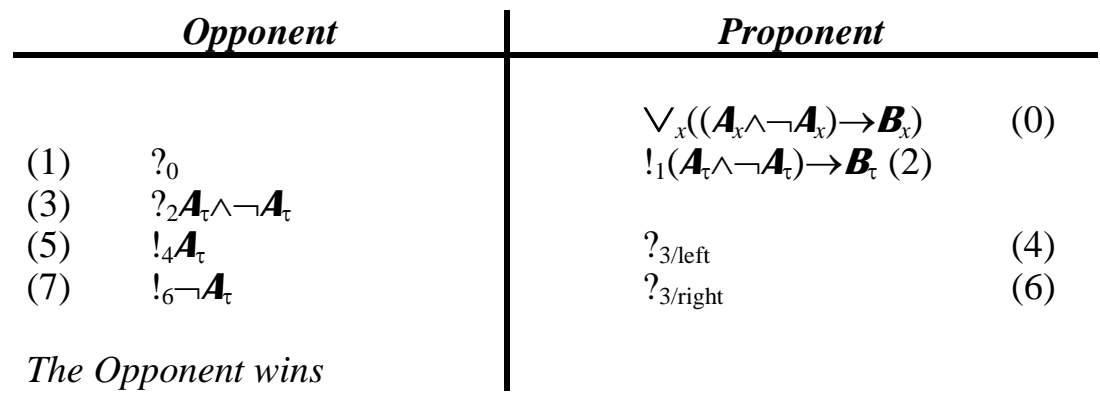

The Proponent loses here because (according to the general negative literal rule) he is not allowed to attack move (7) using the Opponent's move (5).

Similarly, the literal rule blocks the validity of $\vee_{x}\left(\boldsymbol{A}_{x} \rightarrow\left(\neg \boldsymbol{A}_{x} \rightarrow \boldsymbol{B}_{x}\right)\right)$ and the quantified forms of other non-paraconsistent formulae.

Here again it is possible to define quantified literal dialogues for intuitionistic and classical logic. Let us consider an example of a thesis which is not intuitionistically but classically winnable: A quantified literal dialogue in $\mathbf{L}-\mathbf{D}^{\mathbf{i}}$ for $\wedge_{x} \neg \neg \boldsymbol{A}_{x} \rightarrow \neg \neg \wedge_{X} \boldsymbol{A}_{x}$ runs as follows:

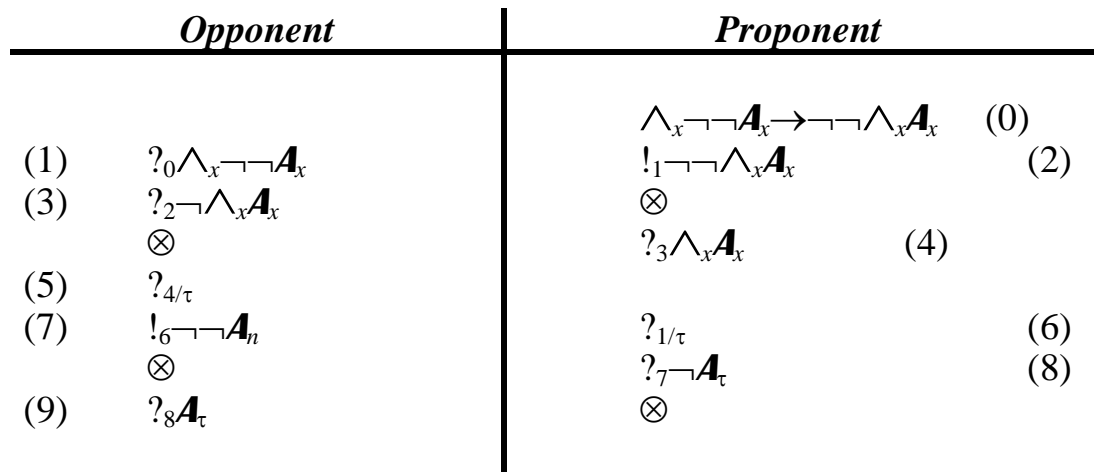


The Proponent loses in $\mathbf{L}-\mathbf{D}^{\mathbf{i}}$ because he is not allowed to defend himself against the attack of the Opponent in move (5) - the last Opponent's attack not already defended by the Proponent was stated in move (9).

The Proponent wins in $\mathbf{L}-\mathbf{D}^{\mathbf{C}}$ because the restriction mentioned above does not hold. Thus the Proponent can answer the attack of move (5) with move (10) in the following dialogue in (quantified) L-DC and win:

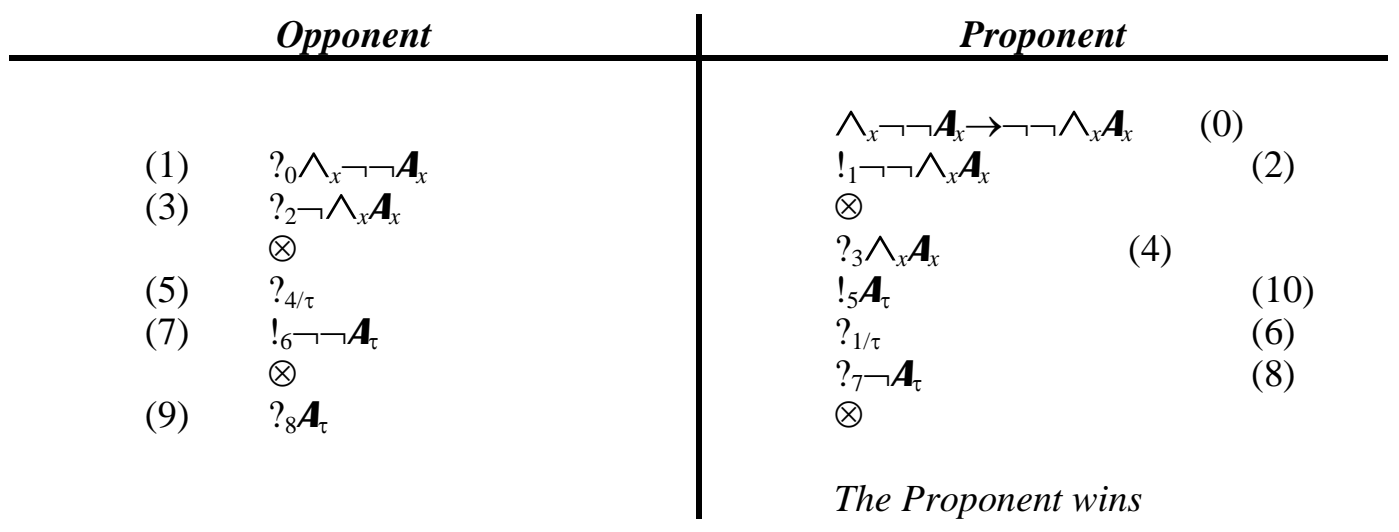

It is possible to define tableaux for the winning strategies which correspond to these dialogue systems - see Rahman/Carnielli [1998]. To obtain paraconsistent tableaux systems for Frege's Nightmare add the following restriction to the closing rules:

- Paraconsistent Restriction:

Check after finishing the tableau and before closing branches that for every elementary $\mathbf{P}$ statement (in which no constants labelled with an asterisk occur and) which follows from the application of an $\mathbf{O}$-rule to the corresponding negative $\mathbf{O}$-literal (i.e. for every attack on a negative $\mathbf{O}$-literal) there is an application of a $\mathbf{P}$-rule to a negative $\mathbf{P}$-literal which yields an $\mathbf{O}$-positive literal with the same atomic formula as the above-mentioned attack of the Proponent. Those elementary $\mathbf{P}$-attacks on the corresponding negative $\mathbf{O}$-literals which do not meet this condition cannot be used for closing branches and can thus be deleted.

The idea of the permissive interpretation is, that paraconsistency does not necessarily leads to accept true contradictions:

I suggest to address the inconsistency issue differently. We may well explore the rich representational devices allowed by the use of paraconsistency in inconsistent domains, but withholding any claim to the effect that there are 'inconsistent objects' in reality. (Da Costa [1998], S. 33).

This allows for the accommodation of inconsistency by aknowledging that it is not a permanent feature of reality to which theories must correspond, but is rather a temporary aspect of such theories [...]. In this view, to accept a theory is to be committed, not to believing it to be true per se, but to holding it as if it were true, for the purposes of further elaboration, development and investigation. (Da Costa / Bueno / French [1998b], S. 616-617).

Frege's Nightmare is a logic that takes the non ontological commitment of inconsistencies seriously. That is, the temporary acceptance of inconsistencies will be abandoned as soon as the singular terms occurring in the elementary propositions producing this inconsistencies are ontologically committed. In other words, if the Proponent has accepted the Opponent's inconsistency $\boldsymbol{A}_{\tau} \wedge \neg \boldsymbol{A}_{\tau}$ he accepted also that the constant $\tau$ carries no ontological commitment. More precisely in Frege's Nightmare the following holds:

$\left(\boldsymbol{A}_{\tau} \wedge \neg \boldsymbol{A}_{\tau}\right) \rightarrow \neg \vee_{x}\left((\mathrm{x}=\tau) \wedge\left(\boldsymbol{A}_{\tau} \wedge \neg \boldsymbol{A}_{\tau}\right)\right)$. 
This approach to paraconsistency blocks triviality for the literal case only, that is, a thesis of the form $((a \wedge b) \wedge \neg(a \wedge b)) \rightarrow c$ is still valid. One way to see the literal rule is to think of it as distinguishing between the internal or copulative negation from the external or sentential negation. ${ }^{10}$ That is, in the standard approaches to logic, the elementary proposition $\boldsymbol{A}_{n}$ has the internal logical form: $n \varepsilon \boldsymbol{A}$ (where $\varepsilon$ stands for the copula: $n \underline{\text { is } \boldsymbol{A}}$ ) and the negation of it the form: $n \varepsilon^{\prime} \boldsymbol{A}$ ( $n$ is not $\boldsymbol{A}$ ). Now in this standard interpretation the negative copula is equivalent to the expression $\neg A$, where $A$ can also be complex. This equivalence ignores the distinction between the internal (copulative) form and the external or sentential form of elementary propositions. The literal approach to paraconsistency takes this distinction seriously with the result that contradictions which cannot be carried on at the literal level should be freed of paraconsistent restrictions. This seems to be the core of the permissive interpretation of paraconsistency: it makes sense to ask for the ontological commitment (or non commitment)of elementary contradictions not of complex ones. The distinction between a copulative and a sentential negation reflects this fact. But this is not the same as to say that the paraconsistency should not be introduced at the level of complex propositions: actually it can be, but with another motivation other than stating propositions with and about contradictory objects ${ }^{11}$.

\section{Conclusions}

This article is one of a series based on the seminar "Erweiterungen der Dialogischen Logik" ("extensions to dialogical logic") held in Saarbrücken in the summer of 1998 by Shahid Rahman and Helge Rückert. The same seminar has motivated the publication of The Dialogical Approach to Paraconsistency by Rahman and Carnielli [1998], On Dialogues and Ontology. The Dialogical Approach to Free Logic by Rahman Rückert and Fischmann,[1998], Dialogische Modallogik für T, B, S4 und S5 [1998] and Dialogische Logik und Relevanz [1998] and Die Logik der zusammenhängenden Aussagen: ein dialogischer Ansatz zur konnexen Logik by Rahman and Rückert. One important aim of these articles (and the present paper) is to show how to build a common semantic language for different non-standard logics in such a way that 1 . the semantic intuitions behind these logics can be made transparent, 2. combinations between these logics can be easily achieved, 3. a common basis is proposed for discussion of the philosophical consequences of these logics - the philosophical point here is to undertake the task of discussing the semantics of non-classical logics from a pragmatical point of view which commits itself neither to a correspondence theory of truth nor to a possible-worldsemantics.

One of the consequences of the dialogical approach is that two of the above mentioned logics can be seen as extending the formal rule for elementary propositions, namely free and paraconsistent logics. This offers a perspective of these logics which seems to be close to Hugh MacColl's reflections on symbolic existence and demands a new concept of logical form. This new concept of logical form should allow valid and invalid forms to be differentiated without going back to a mere syntactic notion - but this is another interesting story.

\section{Acknowledgements}

\footnotetext{
10 The difference between internal and external negation has been worked out for other purposes by A. A. Sinowjew (Sinowjew 11 [1970] and Wessels/Sinowjew [1975]).

The motivation is that of blocking triviality. This can be achieved by means of restricting the number of attacks. More precisely a dialogical paraconsistent logic results from combining the literal rule with the following structural rule: Dual intuitionistic Rule:

In any move, each player may defend himself of every attack or he may attack the last (complex) defence.

If the Proponent starts and attack with the atomic formula $a$ introduced before by the Opponent in move n, he can not start another attack based in an application of the formal rule to the same move $\mathrm{n}$.

After an attack by $\mathrm{X}$ on a negation no other attack by $\mathrm{X}$ is possible.

Thus, as soon as, say X, defends himself from an attack of Y, Y can only attack this defence if complex or the anterior one if this defence is not complex (see Rahman / Roetti [1999]).
} 
The results of this paper are the achievements of a collaboration project between the Archives - Centre d'Etudes et de Recherches Henri Poincaré (Prof. Gerhard Heinzmann), Université Nancy 2 and FR 5.1 Philosophie (Prof. Kuno Lorenz), Universität des Saarlandes, supported by the FritzThyssen-Stiftung which I wish to thank expressly.

I also wish to thank Eric Krabbe, Narahari Rao (Saarbrücken), one anonymous referee and Helge Rückert (Saarbrücken) for their critical comments on earlier versions of this paper and Mrs. Cheryl Lobb de Rahman for her careful grammatical revision.

\section{References}

Astroh, M.

[1996] Präsupposition und Implikatur. In: M. Dascal / D. Gerhardus / K.Lorenz / G.Meggle, Sprachphilosophie / Philosophy of

Bremer, M.

[1998] Wahre Widersprüche: Einführung in die parakonsistente Logik. Sankt Augustin: Academia.

Da Costa, N. C. A

[1974] On the theory of inconsistent formal systems. Notre Dame Journal of Formal Logic, v. 15, 497-510.

[1998] Paraconsistent Logic. In: Stanislaw Jáskowski Memorial Symposium. Paraconsistent Logic, Logical Philosophy, Mathematics \& Informatics at Torún, 29-35.

Da Costa, N. C. A / Alves, E. H.

[1977] A semantical analysis of the calculi $C_{n}$. Notre Dame Journal of Formal Logic, vol. XVI n. 4, 621-630.

Da Costa, N. C. A / Bueno, O. / French, S.

[1998a] Is there a Zande Logic? History and Philosophy of Logic, vol. XIX n. 1, 41-54

[1998b] The Logic of Pragmatic Truth. Journal of Philosophical Logic. 603-620, vol. XXVII.

Felscher, W. [1985]

Jaskowski, S.

[1948] Rachunek zdan’ dla systemów dedukcyjnych sprzecznych. Studia Soc. Scient. Torunensis, Sec. A 1, n.5, 55-77 (English translation in [1969])

[1969] Propositional Calculus for Contradictory DeductiveSystems (english translation of [1948]). Studia Logica 24, 1969, 143157.

Lorenzen, P. / Lorenz, K.

[1978] Dialogische Logik. Darmstadt: Wissenschaftliche Buchgesellschaft

MacColl,

[1880] Symbolical Reasoning. Mind, vol. 5, 45-60.

[1902] Symbolic Reasoning (IV). Mind, vol. 11, 352-368.

[1905a] Symbolic Reasoning (VI). Mind, vol. 14, 74-81.

[1905b] Existential import. Mind, vol. 14, 295-6.

[1905c] The existential import of propositions. Mind, vol. 14, 401-2.

[1906] Symbolic Logic and its Applications, London/New York/Bombay: Longmans, Green \& Co.

Rahman, S.

[1993] Über Dialoge, protologische Kategorien und andere Seltenheiten. Frankfurt a. M. / Berlin / NewYork / Paris / Wien: Peter Lang.

[1997a] Hugh MacColl: Eine bibliographische Erschließung seiner Hauptwerke und Notizen zu ihrer Rezeptionsgeschichte. History and Philosophy of Logic, vol. 18, 165-183.

[1997b] Hugh MacColl's criticism of Boole's formalisation of traditional hypotheticals. Appears in J. Gasser (ed.), 150 years of mathematical analysis of logic, Boston/Basel/Berlin: Birkhäuser.

[1997c] Die Logik der zusammenhängenden Behauptungen im frühen Werk von Hugh McColl. Appears in Boston / Basel / Berlin: Birkhäuser.

[1998] Redundanz und Wahrheitswertbestimmung bei Hugh MacColl. FR 5.1 Philosophie - Universität des Saarlandes, Memo Nr. 23, September 1998.

Rahman, S. / Carnielli, W.A.

[1998] The Dialogical Approach to Paraconsistency. FR 5.1 Philosophie, Universität des Saarlandes, Bericht Nr. 8, July 1998 (appears also in: D. Krause: The work of Newton da Costa, Río de Janeiro: Kluwer - in print).

Rahman, S. / Roetti, J. A.

[1999] The Dual of Intuitionism and the Non-Committal Formulation of Paraconsistency. (in preparation).

Rahman, S. / Rao, N.

[1998] Die logische Kompetenz und die Theorie der mentalen Modelle. FR 5.1 Philosophie, Bericht Nr. 9, July 1998 (appears also in: Philosophia Scientiae 1999).

Rahman, S. / Rückert, H.

[1997] Die pragmatischen Sinn- und Geltungskriterien der Dialogischen Logik. Philosophia Scientiae:, (3) 3, 1998-1999, 145-170.

[1998a] Dialogische Logik und Relevanz, FR 5.1 Philosophie, Universität des Saarlandes, Memo Nr. 26 , July 1998.

[1998b] Die Logik der zusammenhängenden Aussagen: ein dialogischer Ansatz zur konnexen Logik, FR 5.1 Philosophie,

Universität des Saarlandes, Memo Nr. 28, December 1998.

[1999] Ways of understanding Hugh MacColl's concept of simbolic existence. Nordic Journal of Philosophical Logic, 1999, vol.

Read, S.

[1994] Thinking About Logic. Oxford / New York: Oxford University Press.

Rahman, S. / Rückert, H. / Fischmann, M.

[1999] On Dialogues and Ontology. The Dialogical Approach to Free Logic. Logique et Analyse, vol. 160 (1997), $357-374$.

Rao, N.

[1999] Dialogical logic and ontology (in preparation).

Routley, R.

[1979] Exploring Meinong's Jungle and Beyond. Canberra: Canberra Australasian National University.

Rückert, H. / Rahman, S.

[1998] Dialogische Modallogik (für T, B, S4 und S5). FR 5.1 Philosophie, Universität des Saarlandes, Memo Nr. 25, Oktober 1998.

Sinowjew A. A.

[1970] Komplexe Logik. Grundlagen einer logischen Theorie des Wissens. Berlin / Braunschweig / Basel: VEB Deutscher Verlag der Wissenschaften / Friedr. Vieweg + Sohn GmbH / Verlag und C. F. Winter'sche Verlagshandlung.

Sinowjew, A. A. / Wessel H.

[1975] Logische Sprachregeln. Eine Einführung in die Logik. München / Salzburg: Wilhelm Fink Verlag. 
Smullyan, R.

[1968] First-Order Logic. Heidelberg: Springer

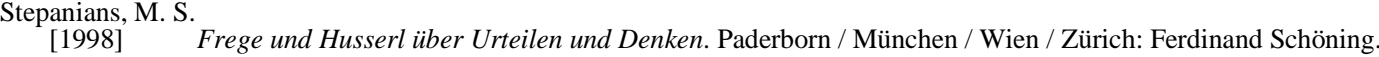

Suárez, F.

[1960] Disputationes Methaphysicae - Disputaciones Metafísicas. Madrid: Gredos - Biblioteca Hispánica de Filosofía. 